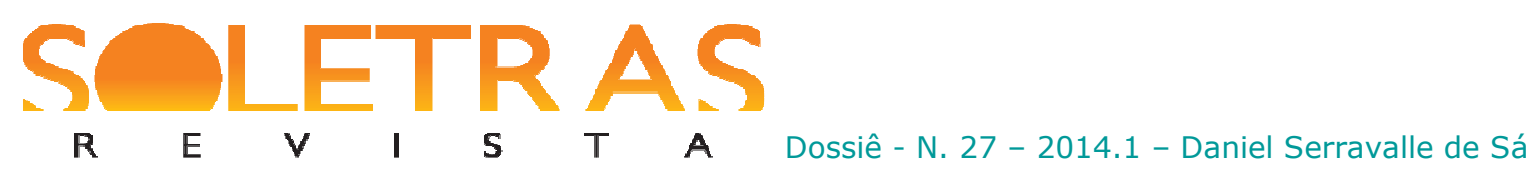

\title{
Memento mori: o zumbi no Gótico americano
}

\author{
Daniel Serravalle de Sá ${ }^{1}$ \\ Universidade Federal de Santa Catarina
}

\begin{abstract}
Resumo: O presente artigo tem como objetivo debater o desenvolvimento da figura do zumbi dentro do contexto do Gótico americano com ênfase em produções cinematográficas dos séculos XX e XXI. Argumenta-se aqui que os zumbis funcionam como uma metáfora cultural de ampla maleabilidade, sendo capazes de refletir uma gama de questões sociopolíticas as quais respondem a conjunturas históricas específicas. De modo mais amplo, discute-se como o zumbi simboliza uma preocupação humana permanente com a decadência do corpo e com morte. Baseando-se em cineastas como Victor Halperin, George Romero, Joe Dante e teóricos como June Pulliam, Kyle Bishop e Elspeth Probyn, argumenta-se que o zumbi é um personagem singular do Gótico no continente americano, cujas raízes não fazem parte do Gótico europeu.
\end{abstract}

Palavras-chave: Zumbi. Gótico americano. Cinema de horror. Literatura e História.

Em tempos recentes, o interesse pela figura dos zumbis vem se expandindo rapidamente, popularizados através de livros, filmes, seriados de TV, videogames, quadrinhos e outras formas ficcionais. Nos Estados Unidos, as narrativas de zumbi têm proliferado sob a designação de American Gothic, ou Gótico americano, uma categorização ampla que compreende desde romances fundacionais da identidade nacional norte-americana, a exemplo de Wieland (1798), de Charles Brockden Brown, e The Last of the Mohicans (1826), de Fenimore Cooper; passando pelo imaginário gótico de Salem, na Nova Inglaterra, com suas bruxas, tribunais e fogueiras, representadas na escrita de Nathaniel Hawthorne e Arthur Miller; o horror cósmico de H. P. Lovecraft; os contos do inigualável Edgar Allan Poe; o Gótico sulino de Flannery O’Connor, William Faulkner e Eudora Welty, até os filmes de Stephen King.

Essa produção cultural, muito variada e diversa entre si, não se comporta exatamente como um gênero, mas como um campo discursivo no qual predominam tendências poéticas que envolvem o desmantelamento do nacional, tensões históricas (conflitos entre forças antagônicas em um dado espaço-tempo), questões de alteridade (cultural, sexual e racial) e

\footnotetext{
${ }^{1}$ Professor Adjunto do Departamento de Língua e Literatura Estrangeiras da Universidade Federal de Santa Catarina. Doutor em Latin American Cultural Studies pela The University of Manchester, Grã-Bretanha (2010). Tem experiência nas áreas de Literatura e Cinema, atuando principalmente nos seguintes temas: teoria e crítica literária e cultural, literatura e história, análise de filmes. Nos últimos anos, tem escrito sobre o Gótico e suas manifestações em diferentes contextos culturais.
} 
estruturações ou situações narrativas que colocam o leitor na fronteira da dissolução simbólica. Críticos como Donald Ringe (1982) e Louis Gross (1989) tentaram organizar essas tendências polivalentes existentes no Gótico americano em função de um relato coeso e historicamente consistente. Entretanto, tentativas de uniformizar e tornar essa pluralidade compreensiva, ou seja, atingir consenso crítico, não são de todo convincentes, talvez nem desejáveis. Robert Martin e Eric Savoy afirmam que o Gótico americano pode ser mais bem entendido como uma série de “'intervenções” que exploram questões específicas nas histórias de gênero e raça, nas culturas das cidades e escândalos e sensações, na psicodinâmica da representação a fim de avançar paradigmas teóricos distintos e particulares" (1998, p. vii). ${ }^{2}$ A ideia do Gótico americano enquanto uma "intervenção" que não pode ser apreendida de forma sinedótica $^{3}$ parece mais adequada para explicar a diversidade, o caráter essencialmente discursivo e recorrente do Gótico, cujo conjunto de metáforas se prolifera em diferentes formas de expressão artística e disciplinas.

A figura do zumbi ocupa um lugar especial dentro do Gótico, pois não tem origem nas matrizes europeias, na quais o imaginário gótico emana de medos que persistiram da Idade Média: o repúdio britânico ao catolicismo medieval, os conflitos entre a burguesia ascendente e a antiga aristocracia, a mistura entre fascínio e terror que levantes revolucionários do século XVIII causavam nos conservadores ingleses. Além disso, os zumbis não são personagens baseados em textos literários, como Frankenstein (1818) e Drácula (1897), cuja existência torna-se de certo modo uma referência limitadora, mas fazem parte de um sistema mais antigo de mitologia e lendas, que permite uma significação mais flutuante e uma possibilidade de ressonância de significados sociais e psicológicos mais versátil entre diferentes períodos históricos. ${ }^{4}$

Zumbis são geralmente relacionados ao vodu, prática religiosa com raízes na África que, ao ser trazida para o continente americano, se destacou na região do Caribe, em particular no Haiti e em Cuba, mas que também se exprime de diferentes formas em outros

\footnotetext{
${ }^{2}$ No original: "interventions" that explore specific issues in the histories of gender and race, in the cultures of cities and scandals and sensations, in the psychodynamics of representation in order to advance particular and distinct theoretical paradigms.

${ }^{3}$ De sinédoque: consiste na atribuição da parte pelo todo (pars pro toto).

${ }^{4}$ Outi Hakola (2012) utiliza o conceito de "morto-vivo" enquanto uma categorização ampla que abrange vampiros, zumbis e múmias. Todavia, entende-se aqui que há diferenças fundamentais entre o zumbi e outros tipos de mortos-vivos. O zumbi caracteriza-se por ser cadáver reanimado ou por ser um corpo vivo que está possuído, subordinado à outra vontade. Se compreendido nesse sentido, golems e criaturas semelhantes à criação do Dr. Frankenstein não se enquadram nessa definição. Golems são seres criados a partir de outras formas de matéria. O monstro de Frankenstein é um ser criado de partes de diferentes pessoas, em oposição um único corpo reanimado. Múmias e vampiros, por exemplo, apesar de serem cadáveres reanimados, possuem vontade própria e não estão subordinados à vontade de alguém.
} 


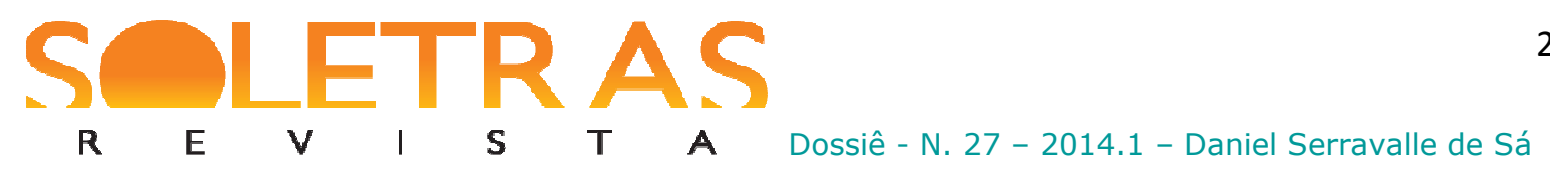

locais, a exemplo da Bahia e do Rio de Janeiro. Apesar da diversidade com que se manifesta, há elementos que sugerem unidade na origem dessas práticas religiosas, as quais têm por base exemplos de incorporação, sacrifício e magia, na forma de oferendas feitas para santos e orixás - representando a dualidade de poderes corporais e espirituais. Presos no limiar da vida e da morte, com seus olhares vazios e mentes ausentes, os zumbis do vodu ganham ares fantasmagóricos, sendo este um ponto específico de associação com o universo sobrenatural que tem caracterizado o Gótico e seus espectros desde Horace Walpole, em 1764. No entanto, ainda que se possa estabelecer tal ligação com o Gótico europeu, o zumbi é em essência uma criatura originária da América Caribenha e Latina, nascida na tradição popular, assim como lobisomens, vampiros e fantasmas, mas que não possui uma fundação literária ou narrativa primordial que estabeleceu e codificou suas características, passando efetivamente do folclore para as telas.

Pretende-se aqui discutir a maleabilidade da figura do zumbi enquanto metáfora cultural dentro do contexto do Gótico americano, demonstrando que seu significado varia em função de ciclos históricos e destacando como o zumbi tem sido utilizado para representar uma gama de questões sociopolíticas e ansiedades culturais, a exemplo de escravidão, xenofobia, racismo, horrores da guerra, medo da morte e apreensões sobre a cultura de consumo. Nesse processo de constante atualização, o imaginário mais tradicional relacionado aos mortos-vivos (aquele oriundo das práticas do vodu) vem desenvolvendo novas características de acordo com a visão particular de escritores, diretores e artistas contemporâneos, ecoando diferentes perspectivas sociopolíticas. Apesar da diversidade atual em torno da origem, definição e conceito do zumbi, existem algumas questões centrais que são subjacentes à maioria das obras que o representam. Seja por contaminação viral ou radioativa, lavagem cerebral, feitiçaria, ou outro modo, os processos de "zumbificação" são geralmente relacionados à massificação das opiniões, perda progressiva de capacidade de raciocinar de modo crítico e independente, apatia e insensibilidade emocional. Em última instância, são processos que conduzem à morte do raciocínio e das emoções, com implicações que repercutem no próprio conceito de humanidade.

\section{Imperialismo, escravidão e zumbis}

Durante o século XIX, algumas narrativas de viagem e outros tipos de textos nãoficcionais fizeram referências vagas e inconsistentes aos zumbis caribenhos. Segundo Tony 
Fonseca (2005, p.1240), uma das primeiras referências à palavra zumbi na literatura escrita em inglês se dá via o poeta romântico Robert Southey que, em 1819, utiliza-a como uma metáfora do imperialismo britânico nas Américas, indicando o colonizado destituído de autonomia e vontade própria. Desde então a figura do zumbi tornou-se simbólica da escravidão ou de situações que tornam as pessoas incapazes de lutar contra a miséria da sua condição, de modo que raramente os zumbis são protagonistas das narrativas em que aparecem.

De acordo com pesquisadores como June Pulliam (2007) e Kyle W. Bishop (2010), o zumbi entra na cultura popular com a publicação de The Magic Island (1929), diário de viagem de William B. Seabrook, um aventureiro que viveu no Haiti e coletou histórias sobre zumbis e práticas de vodu. Entre outros relatos de sensacionalismo antropológico, o autor alega ter visto uma vez um homem morto ser ressuscitado. Embora histórias sobre zumbis não fossem algo completamente inédito nos Estados Unidos ou na Europa, o livro de Seabrook iluminou alguns aspectos sobre a incompreendida mitologia haitiana, despertou o interesse ocidental pela figura do zumbi e talvez tenha até causado um certo choque cultural em sua época ao apresentar uma característica temível para o conceito protestante de virtude: a ausência de livre-arbítrio.

White Zombie (1932), dirigido Victor Halperin e estrelado por Bela Lugosi, é um dos primeiros longas metragens sobre zumbis produzidos pela indústria hollywoodiana. ${ }^{5}$ Adaptação livre do relato de Seabrook, o filme mostra trabalhadores de um engenho de açúcar sendo explorados pelo ganancioso dono do moinho, Monsieur Beaumont (Robert Frazer), e manipulados pelo feiticeiro Murder Legendre (Bela Lugosi), que os escraviza através de uma combinação de drogas, hipnotismo e magia negra. Embora muitos dos zumbis que trabalham no engenho sejam inconfundivelmente negros, Legendre e alguns zumbis são mestiços. $\mathrm{O}$ horror central do filme se dá quando o feiticeiro usa suas habilidades para escravizar uma mulher americana, Madeleine (Madge Bellamy), e transformá-la em uma "zumbi branca". Para os fins do enredo não importa se as pessoas de pele escura são escravizadas e exploradas, a única vítima que merece atenção é aquela cuja pele é branca.

Adiante, o potencial inerentemente racista torna-se mais complexo e, de maneira suposta, mais terrível para um determinado tipo audiência, devido ao fato de que o corpo apropriado por captores masculinos é do sexo feminino, sugerindo a possibilidade de

\footnotetext{
${ }^{5} \mathrm{O}$ filme foi moderadamente bem-sucedido nas bilheterias e, posteriormente, Lugosi ainda faria mais quatro filmes de zumbis: The Bowery at Midnight (1942), The Voodoo Man (1944), a comédia Zombies on Broadway (1945), e o infame Plan 9 from Outer Space (1958), o qual não chegou a completar pois faleceu em 1956. 


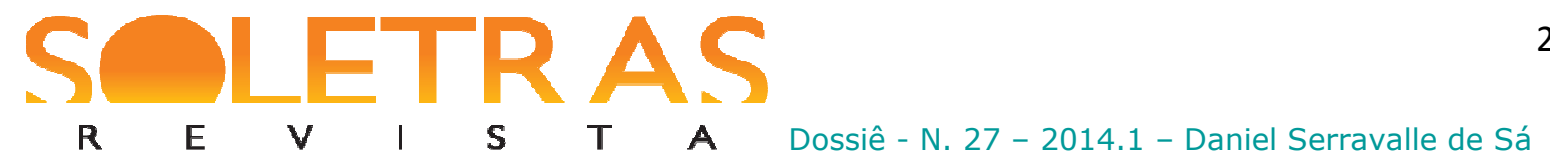

violência sexual. A situação típica dos melodramas góticos, um homem mais velho e experiente que ameaça a segurança de uma personagem feminina indefesa, ganha aqui contornos raciais. Adiante, o filme ecoa o medo de uma insurreição contra a ocupação americana em andamento no Haiti (1915-1934), a qual, entre outros tipos de constrangimentos, obrigava camponeses nativos a construírem estradas e executar trabalhos degradantes. Apesar de ter ajudado a chamar a atenção para a figura do zumbi, o filme de Halperin apresenta uma visão historicamente datada e negativa da cultura e sociedade negra no Haiti. Embora o filme contenha a capacidade de alarmar audiências brancas com a possibilidade de revolução e ameaças à autonomia de mulheres brancas, que seriam exemplos dos efeitos adversos dos mecanismos colonialistas de opressão, faz isso de uma maneira sensacionalista e preconceituosa.

O filme I Walked with a Zombie (1943), dirigido por Jacques Tourneur e produzido por Val Lewton, oferece aos espectadores uma estética cinematográfica de qualidade superior, que lhe rendeu criticas favoráveis e sucesso de bilheteria. Apesar de não se tratar de uma adaptação literária, há certos trechos do filme que dialogam com o romance Jane Eyre (1847), de Charlotte Brontë. O filme apresenta uma visão culturalmente mais adequada à representação da sociedade negra no Caribe, todavia, como outros filmes de zumbi das décadas de 1930 e 1940, não consegue transcender certos estereótipos a respeito das culturas negras e elevar-se acima da paranoia racial. Utilizando-se do cenário exótico do Caribe como ambientação, o filme reafirma a superioridade da cultura branca imperialista e a ausência de consciência política dos nativos que reproduzem dentro da sua própria sociedade a dialética hegeliana de domínio de um grupo sobre outro, na qual o mestre e senhor é encarnado pelo feiticeiro vodu e o escravo pelos zumbis. O filme também pode ser criticado como discurso cultural à luz das teorias de Gayatri C. Spivak (1988) pois, em seu silêncio espectral, o zumbi é um subalterno incapaz de se conectar com a cultura dominante através de qualquer espaço liminar do discurso. Um ponto positivo de I Walked with a Zumbi é que o filme não reduz a religião vodu e os zumbis à mera superstição primitivista, nem retrata seus praticantes como maus ou infantis, ao contrário, à maneira de um documentário etnográfico, ainda que carregado no melodrama, incentiva-se a audiência a manter a mente aberta, e a questão da possessão ou “zumbificação” de Jessica Holland (Christine Gordon) fica sem resolução.

Nesses dois filmes que abriram o caminho para a figura do zumbi dentro da cultura popular norte-americana, o problema central e fonte de terror para uma audiência branca e ocidental não são os dilemas políticos das nações pós-coloniais, mas o risco que os 
protagonistas, em particular as protagonistas femininas, possam ser transformadas em zumbis, pois isso significaria tornar-se subjugadas, possuídas (simbolicamente estupradas) e, em última instância, colonizada por negros não-cristãos.

Apesar de a ação narrativa em ambos os filmes acontecer em território caribenho, e não em solo americano, a temática do zumbi está mais próxima das apreensões norteamericanas e seu projeto colonialista no Novo Mundo do que filmes que se passam na Romênia ou até mesmo na Inglaterra. São obras que aludem à escravidão e, em geral, justificam a presença do homem branco em terras tropicais enquanto elemento "civilizador" que vai organizar o modo de vida primitivo das populações locais. Os zumbis representam o resultado negativo dos horrores do imperialismo, projetando ansiedades relacionadas à escravidão e ao imperialismo, o medo que provém da tentativa de subjugar indevidamente uma cultura nativa e o temor de a cultura branca imperialista de não ser afinal de contas superior.

\section{Zumbis, memento mori, e sociedade de consumo}

O filme The Night of the Living Dead, ou A Noite dos Mortos-Vivos (1968), de George Romero, é um divisor de águas no tropo do zumbi, atualizando o imaginário dos mortos-vivos para questões mais condizentes ao seu tempo e introduzindo modificações que irão alterar significativamente o conceito do personagem. Até então, o zumbi caribenho era apenas um ser desprovido de vontade própria, que não oferecia maiores perigos àqueles que estavam em sua volta, sendo que o principal medo dos espectadores era a possibilidade de ser transformado em um zumbi. Romero recria o zumbi caribenho incorporando as contribuições do folclore africanista e misturando-as com o imaginário do canibal. A ideia de hibridização entre o zumbi e o canibal inaugura uma nova fase da figura do zumbi dentro da cultura popular norte-americana, baseada em imagens de feitiçaria, antropofagia e terror. A partir de Romero, as características do zumbi têm se modificado de modo expressivo, com ênfase no gore (derramamento de sangue ou "sangue e tripas") e na decomposição do corpo humano, ressaltando os aspectos mais grotescos da morte. Seu conceito de "apocalipse zumbi", situação em que o mundo civilizado é abatido por uma infestação zumbi global, tornou-se um marco da arte popular moderna.

Ambientado em um subúrbio de Pittsburgh, os zumbis de Romero não possuem qualidade mágicas ou sobrenaturais, eles são criados por uma radiação, algum tipo de 
tecnologia cuja origem exata não fica bem explicada no filme. Os perigos da radiação já havia sido um tema bastante explorado por filmes de ficção científica da década de 1950, cujo subtexto ecoou no contexto sócio histórico norte-americano temores a respeito da energia nuclear e inquietações relacionadas à Guerra Fria. O medo de um apocalipse nuclear ainda era algo remanescente, mesmo ao final da década de 1960, e pode ser notado em A Noite dos Mortos-Vivos no debate entre os personagens sobre qual seria o melhor lugar para se proteger e sobreviver: sótão ou porão? Presos em ambientes claustrofóbicos, as pessoas discutem e se desentendem, e as brigas internas levam à desgraça do grupo. Curiosamente, a palavra "zumbi” não aparece nos diálogos do filme, os mortos-vivos são chamados de ghouls. ${ }^{6} \mathrm{~A}$ atenção visual dada a corpos em decomposição e a brutalidade dos assassinatos cometidos pelos mortos-vivos sugere que um dos aspectos centrais do filme é a onipresença do memento mori, expressão latina que significa "lembre-se da morte" ou "lembre-se que vai morrer", pois os zumbis de Romero embotam os limites entre vida e morte, monstro e vítima, fazendo com que o espectador questione a diferença essencial entre zumbis e humanos.

Somente em Dawn of the Dead, ou O Despertar do Mortos (1978), é que Romero passa a utilizar o termo zumbi. A narrativa toma por base o mesmo cenário de contaminação radioativa do filme anterior e, após a infestação zumbi atingir a Filadélfia e boa parte dos Estados Unidos, um grupo de desconhecidos se refugia dentro de um shopping center, bloqueando o acesso à edificação. Ao se sentirem seguros em seu novo espaço habitacional, o qual pode ser considerado o templo ou o novo santuário do mundo moderno, os personagens adotam um comportamento hedonista, consumindo sem moderação diferentes tipos de produtos. O filme pode ser interpretado como uma crítica à sociedade de consumo ao demonstrar que os hábitos de consumo estão tão arraigados dentro das pessoas que nem mesmo diante da aniquilação iminente eles conseguem se desligar de certos tipos de bens e desejos de compra. O consumo irracional é um tema central no filme: enquanto os zumbis têm como principal objetivo comer carne humana, os personagens presos dentro do shopping se abstraem da situação séria em que se encontram e desejam unicamente consumir os acessórios e produtos disponíveis sem precisar pagar pelos itens.

Além dos zumbis, outros monstros já foram usados metaforicamente para descrever a cultura ocidental de consumo, uma civilização de consumo excessivo e fome insaciável que

\footnotetext{
${ }^{6}$ Segundo Scott Connors (2007, p. 262-263), apesar de a palavra ghoul ser usada figurativamente na designação de uma variedade de monstros, ela está sendo empregada no filme de Romero de maneira equivocada. Originária de lendas árabes, o ghoul é um demônio devorador de cadáveres e não um corpo ressuscitado. A palavra entra no idioma inglês através de obras literárias a exemplo do romance gótico Vathek (1786), de William Beckford; do poema The Ghoul (1897), de Edward Lucas White; e do conto Amina (1906) de H. P. Lovecraft. 
exige sacrifícios de sangue em atos de violência, às vezes literalmente, se pensarmos nas guerras, e, de maneira geral, utiliza corpos humanos para o lucro. Karl Marx, por exemplo, afirma que "o capital é trabalho morto, que apenas se reanima, à maneira dos vampiros, chupando trabalho vivo e que vive tanto mais quanto mais trabalho vivo chupa" (1983, p. 189). Ao descrever o capitalismo industrial como um vampiro que suga o sangue dos trabalhadores, Marx aponta para o caráter essencialmente fetichista dos bens de consumo e para a alienação do trabalhador que troca sua mais-valia ou seu "sangue" - a força vital - se pensarmos na metáfora do vampiro, por objetos "mortos". Elspeth Probyn se vale da figura do canibal para discutir a história do apetite ocidental, o qual ela chama de gut ethics ou ética do intestino (2000, p. 99). Probyn emprega a metáfora do canibalismo enquanto símbolo dos anseios europeus em relação a bens de consumo. Ela interpreta essa forma de capitalismo como uma deformação da realidade, uma política socioeconômica que cedeu à obsessão de um consumo desenfreado e sem limites. Ainda segundo a autora, a solução estaria em ações de consumo consciente, uma ética ou prática de contenção.

Apesar de imagens de vampiros e canibais terem sido usadas para questionar de forma simbólica o consumo de mercadorias e as relações materiais entre os seres humanos, a figura do zumbi parece mais adequada para falar dessas questões, principalmente quando pensamos na formação das sociedades pós-coloniais no continente americano e, em particular, nas sociedades da América Central e Latina, onde o consumo psíquico e corporal é mais profundo e onipresente. Embora o canibal já tenha adquirido, em diferentes níveis, um certo status quo em conexão ao modo como as relações entre colonizado e colonizador são tradicionalmente compreendidas, em se tratando de exemplos e considerações sobre consumo no contexto póscolonial, a figura do zumbi enquanto metáfora cultural tem muito a oferecer, pois opera dentro da dimensão histórica do trabalho forçado, apatia política, esvaziamento da memória e novos tipos de servidão transpostos para a conjuntura capitalista do século XX e XXI. Em outras palavras, enquanto o canibal se presta para discussões relacionadas ao projeto colonialista europeu da fase de consolidação capitalista, com seus procedimentos de exploração, opressão, domesticação e "consumo" dos povos nativos, a metáfora do zumbi reflete contextos sócio históricos pós-coloniais os quais dizem respeito a um conjunto específico de relações corporais, de violência, formas degradadas de trabalho que fazem parte da formação da América Latina.

A metáfora do canibalismo já foi, inclusive, encarada positivamente durante o modernismo brasileiro por um grupo de escritores e artistas para quem a devoração 
antropofágica era uma forma de resistência contra a dominação cultural. Ao invés de negar ou combater de forma acirrada a influência cultural-material estrangeira, textos como o Manifesto Antropófago (1928), de Oswald de Andrade, e a Revista de Antropofagia (primeira dentição 1928, segunda dentição 1929), de Alcântara Machado, Raul Bopp e Geraldo Ferraz, problematizaram o significado metafórico e literal do canibalismo. Para os brasileiros, o tropo do canibalismo se torna a base de uma estética que buscava sintetizar as vanguardas europeias de modo criativo. Assim, o canibalismo se torna uma forma de empoderamento na qual o corpo individual é projetado enquanto corpo sociopolítico; e o ato de comer, ingerir, vomitar torna-se uma forma de resistência contra as relações internacionais de poder. Se o movimento antropofágico buscou igualar posições através da ressignificação dos aspectos negativos do canibal, o zumbi permanece simbólico das relações desiguais. Qualquer esforço para embarcar em um projeto cultural de re-imaginar tais desigualdades, seja no Haiti, em Cuba ou no Brasil, e apesar das esporádicas tentativas emancipatórias de escravos rebeldes como Zumbi de Palmares e outros agentes revolucionários, as sociedades pós-escravagistas da América Caribenha e Latina continuam refém das práticas de consumo ditadas pelos países dominantes.

Estendendo o significado dos filmes de Romero que exploram o tema do consumo irracional corporificado na figura do zumbi, o argumento aqui é as relações de dominação se mantém no século XXI tal como foram no século XX. A história se repete em diferentes graus e em diversas esferas, desde a comodificação dos corpos subalternos para trabalho e sexo, “comidos" por aqueles em posições de poder, passando pela devoração do capital cultural dos países dominados, a exemplo do conhecimento de plantas nativas pelas grandes indústrias farmacêuticas, até o controle das economias nacionais via políticas financeiras que servem para manter e reafirmar a posição dos países dominantes enquanto fonte de conhecimento e poder. Os países periféricos continuam sendo consumidos, mas o sentimento de morbidez, as inquietações oriundas do sentimento de culpa daqueles que sabem que exploram, e a lembrança da morte apesar da riqueza ganha às custas dos explorados continuam assombrando a cultura dos europeus e americanos.

\section{Dos anos 80 ao século XXI: a maleabilidade do zumbi}

Em 1983, os zumbis saem em definitivo do circuito de filmes B e consolidam seu lugar na cultura popular e de massa com o lançamento do videoclipe Thriller, de Michael 
Jackson. Apesar da disposição ou tentativa de aterrorizar o público, o videoclipe pode ter sido considerado cômico por muitas pessoas que, ao assistirem a dança dos zumbis com o "rei do pop", perceberam os monstros como seres caricatos e exagerados. Tal percepção pode ter sido reforçada nos anos seguintes com o lançamento da paródia The Return of the Living Dead, ou A Volta do Mortos-Vivos (Dan O'Bannon, 1985). Entretanto, essas intervenções satíricas no imaginário dos zumbis não foram suficientes para anular a propensão dos mortos-vivos de causar terror, talvez porque ver corpos humanos em decomposição seja um lembrete impactante sobre a finitude da vida. As intervenções satíricas tampouco conseguiram invalidar o potencial dos zumbis enquanto metáfora social, como se pode notar no filme The Serpent and the Rainbow, ou A Maldição do Mortos-Vivos (1988), de Wes Craven, no qual o simbolismo dos "corpos infecciosos" sugere o problema da AIDS no Haiti e em outros lugares do mundo.

Em tempos mais recentes, a figura do zumbi continua crescendo em popularidade e se propaga no século XXI por meio de diferentes itens culturais, a exemplo de videogames (Left 4 Dead e DayZ), quadrinhos (Marvel Zombies e The Goon: Nothin' But Misery) e séries de TV (The Walking Dead e Grimm). Nesse processo de expansão, algumas características criadas por George Romero, em particular a fome por cérebro e carne humana (que não existem no zumbi caribenho), se consolidaram como parte do imaginário zumbi recriado no contexto do Gótico americano, enquanto outras características continuam em plena mutação. Ao invés de apáticos e letárgicos, a maioria dos zumbis contemporâneos são rápidos e implacáveis, como se pode notar em alguns dos seriados de TV e videogames mencionados, assim como nos filmes 28 Days Later ou Extermínio (2002), de Danny Boyle, e I Am Legend, ou Eu sou a Lenda (2007), de Francis Lawrence.

O zumbi continua sendo atualmente uma metáfora cultural agregadora de diversos sentidos, inclusive com significações conflitantes entre si. Por exemplo, no livro Obama Zombies (2010, p. 9), Jason Mattera se vale do signo do zumbi para atacar o que ele considera a "mumificação mental” de uma geração de jovens americanos, vítimas de um engodo político articulado pelo partido democrata e apoiado pela grande mídia. Contra o que ele considera falácias políticas do governo de Barack Obama (investimentos na saúde pública, preocupação com a ecologia, busca de justiça social), Mattera faz uma apologia veemente ao capitalismo autorregulatório, defende a livre iniciativa, a meritocracia social e discorre contra a taxação diferenciada das grandes fortunas. Em oposição ao discurso populista e às políticas assistencialistas, o autor denuncia como o "discurso liberal" de Obama, com a ajuda da 
grande mídia, tem feito uma lavagem cerebral na sua geração, criando uma horda de jovens acéfalos com promessas que são socialmente e economicamente inviáveis.

Anteriormente, quando o partido republicano governava os Estados Unidos, diversos filmes de zumbi foram lançados em oposição ao projeto político de cunho militarista representado pelos dois presidentes da família Bush. Uma das críticas mais pungentes feita contra a política da "guerra gloriosa" conduzida pelos Bush, cujo discurso frequentemente recorre a palavras como "nacionalismo" e "liberdade", foi Homecoming (2005), episódio da série Masters of Horror, dirigido por Joe Dante. O subtexto político, tão habitual em narrativas de terror, é abertamente dispensado aqui, pois soldados mortos em combate no Iraque literalmente saem dos seus caixões cobertos com a bandeira americana para votar. Juntam-se a eles veteranos mortos no Vietnam, na Primeira e Segunda Guerra Mundial e na Guerra Civil. A ideia aqui é que "o povo" acordou para pedir o fim da guerra. Instaura-se então um debate nacional para decidir se zumbis têm direito ao voto. Apesar de antagônicas, as duas posições apresentadas acima se valem do mesmo material para debater suas divergências políticas e ideológicas, de modo que o zumbi se mostra uma figura maleável, catalisadora de posições contraditórias cujo alcance varia de valores conservadores à valores liberais.

Dentro da cultura popular americana, a figura do zumbi percorreu uma trajetória que abrange, entre outros tipos de discurso cultural, preocupações com a perda do livre-arbítrio, os horrores da escravidão e do trabalho forçado, xenofobia, os medos oriundos da Guerra Fria, críticas ao consumo e apreensões relacionadas ao trabalho industrial, pânico com doenças infecciosas, divergências ideológicas dentro do espectro político etc. As diferentes conotações são fruto de contextos históricos pontuais que se valem da maleabilidade do zumbi enquanto metáfora cultural para expor seus receios e desassossegos. Todavia, pensando além de contextos históricos específicos, há algumas questões centrais subjacentes à maioria das obras que representam o zumbi. Famintos por cérebro e carne humana, o zumbi é em sua essência uma metáfora cultural que está, de modo literal e simbólico, intrinsecamente relacionada à canibalização do homem pelo homem. Quando deixamos de pensar em nossos corpos enquanto consumidores de comida para pensarmos neles enquanto alimento para os outros, ultrapassa-se uma fronteira que diz respeito aos excessos do ser humano em sua capacidade de consumir, diante, se avançarmos esse pensamento, ultrapassa-se a fronteira do próprio conceito de humanidade. O zumbi, esse ícone do horror moderno, é uma constante lembrança 


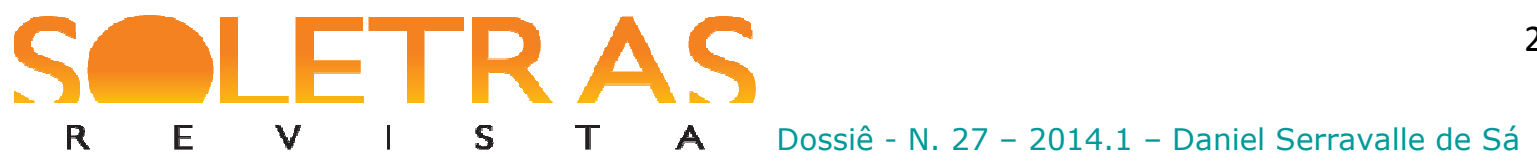

de que todos os seres humanos são perecíveis (memento mori) e que tentar controlar o destino, seja pela tecnologia ou pela acumulação de riquezas, é uma arrogância e uma ilusão.

\section{Referências bibliográficas:}

A MALDIÇÃO dos mortos-vivos “The Serpent and the Rainbow”. Direção: Wes Craven. USA: Universal, 1988.

A NOITE dos mortos-vivos "Night of the Living Dead". Direção: George A. Romero. USA: Image Ten, 1968.

A VOLTA dos mortos-vivos “The Return of the Living Dead”. Direção: Dan O'Bannon. USA: Orion, 1985.

ANDEI com um zumbi "I Walked with a Zombie". Direção: Jacques Tourneur. USA: RKO, 1943.

BISHOP, Kyle W. American Zombie Gothic: the rise and fall (and rise) of the walking dead in popular culture. Jefferson, NC: McFarland, 2010.

CONNORS, Scott. The Ghoul. In: JOSHI, S.T. (Org.). Icons of Horror and the Supernatural, volume 1. Westport, CT: Greenwood Press, 2007. p. 243-266.

DAYAN, J. Haiti, History and the Gods. Berkeley and London: University of California Press, 1998.

EU SOU a lenda “I am Legend”. Direção: Francis Lawrence. USA: Warner, 2007.

EXTERMÍNIO “28 Days Later”. Direção: Danny Boyle. GB: British Film Council, 2002.

FONSECA, Tony. Zombies. In: JOSHI, S.T. e DZIEMAINOWICZ, S. (Orgs.). Supernatural Literature of the World. Westport, CT: Greenwood Press, 2005. p. 1240- 1253.

GROSS, Louis S. Redefining the American Gothic. Ann Arbor: UMI Research Press, 1989.

HAKOLA, Outi. Exotic primitivism of death in classical Hollywood living dead films. Ilha do Desterro. Florianópolis, SC, n. 62, p. 219-240, jan.-jun, 2012.

HOMECOMING, episódio 6 do seriado Masters of Horror, temporada 1. Direção: Joe Dante. USA: IDT Entertainments, 2005.

MARTIN, Robert \& SAVOY, Eric. American Gothic: new interventions in a national narrative. Iowa: University of Iowa Press, 1998.

MARX. Karl. O Capital: crítica da economia política. Tradução de Régis Barbosa e Flávio R. Kothe. Coleção Os Economistas, volume I, livro I, tomo I. São Paulo: Abril Cultural, 1983. 


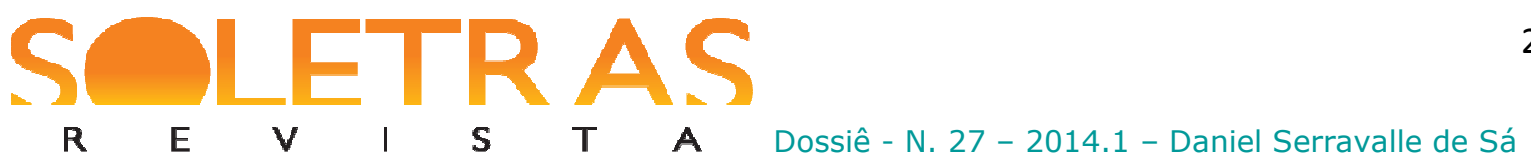

MATTERA, Jason. Obama Zombies: how the liberal machine brainwashed my generation. New York: Threshold, 2010.

O DESPERTAR dos Mortos “Dawn of the Dead". Direção: George A. Romero. EUA: Laurel, 1978.

PROBYN, Elspeth. Carnal Appetites: foodsexidentities. London and New York: Routledge, 2000.

PULLIAM, June. The Zombie. In: JOSHI, S.T. (Org.). Icons of Horror and the Supernatural, volume 2. Westport, CT: Greenwood Press, 2007, p. 723-754.

RINGE, Donald A. American Gothic: imagination and reason in nineteenth-century fiction. Lexington: UP of Kentucky, 1982.

SHELLER, Mimi. Consuming the Caribbean: from Arawaks to Zombies. London and New York: Routledge, 2003.

SPIVAK. Gayatri C. Can the Subaltern Speak?. In: NELSON, C. e GROSSBERG, L. (Orgs.). Marxism and the Interpretation of Culture. Urbana: University of Illinois Press, 1988. p. 271313.

WASSERMAN, Renata R. M. Gothic Roots: Brockden Brown's Wieland, American identity, and American literature. Ilha do Desterro. Florianópolis, SC, n. 62, p. 197-217, jan.-jun. 2012.

ZUMBI branco “White Zombie”. Direção: Victor Halperin. EUA: United Artists, 1932.

\title{
Memento mori: the zombie in the American Gothic
}

\begin{abstract}
This article aims at discussing the development of the zombie within the context of the American Gothic, with an emphasis on film productions of the 20th and 21st centuries. It is argued here that zombies function as highly malleable cultural metaphor; they are able to reflect a range of socio-political issues which depend on specific historical periods. More broadly, the article discusses how the zombie symbolizes a permanent human concern with body decay and death. Based on filmmakers like Victor Halperin, George Romero, Joe Dante, and theoretical as June Pulliam, Kyle Bishop and Elspeth Probyn, I argue that zombies are is an original character of the Gothic in the American continent, whose roots are not part of the European Gothic.
\end{abstract}

Key words: Zombie. American Gothic. Horror film. Literature and History.

Recebido em: 31 de janeiro de 2014.

Aprovado em: 25 de agosto de 2014 . 